Tohoku J. exp. Med., 1971, 103, 317-329

\title{
Contractile Properties of Organ-cultured Intestinal Smooth Muscle
}

\author{
Akira Rikimaru \\ Department of Applied Physiology,* Tohoku University School \\ of Medicine, Sendai
}

RIKIMaRU, A. Contractile properties of organ-cultured intestinal smooth muscle. Tohoku J. exp. Med., 1971, $103(4), 317-329$ — The contractile properties of the smooth muscle of guinea-pig taenia coli in organ culture were investigated in relation to the histochemical observation on its innervation. The smooth muscle preparations were cultured in the medium rich in horse serum and chick embryo extract. They preserved responsiveness to nicotine and transmural stimulation at low frequencies for more than three weeks. On the other hand, those cultured in the medium contained only lower concentration of horse serum and deficient in chick embryo extract lost such responsiveness after two to three weeks of incubation. It is evident from these data that the latter condition of culture would be adequate for the experiment in which the smooth muscle is maintained but the nerve element have to be eliminated. In this condition, the preparations on the 4th day of culture failed to produce a relaxation by transmural stimulation at high frequencies, though it was produced at low frequencies and by nicotine. The fluorescence of eatecholamines disappeared at the same stage of culture, but no supersensitivity to noradrenaline and acetylcholine was observed. Histofluorometric observation of the taenia before culture revealed the presence of intensely fluorescent nerve fibers scattered in the muscular layers and around the nonfluorescent ganglion cells in Auerbach's plexus. Neither fluorescent ganglion cells nor characteristic fluorescence of 5-HT could be observed in Auerbach's plexus. These results strongly confirmed the presence of non-adrenergic inhibitory neurons within the taenia. Histofluorometric data ruled out the possibilities of participation of dopamine and 5-HT in this inhibitory mechanism. The transmitter of the intramural inhibitory neurons did not show any fluorescence by the treatment with formaldehyde vapor.—organ culture; taenia coli; contractile properties; catecholamine fluorescence

Since Harrison (1907) first introduced the method of tissue culture to prove the "neuron theory", tissue culture and organ culture have been widely used and developed by many investigators in various fields.

The changes in form and behavior of muscle in tissue culture have since attracted attention of investigators, and a good deal of works on tissue cultures of skeletal and cardiac muscles have been carried out. But the reports on smooth muscle in tissue culture and organ culture, especially in organ culture, are relatively scarce (see Murray 1965). It must be admitted, therefore, that tissue cul-

Received for publication, October 14, 1970.

* Director: Prof. T. Suzuki. 
ture and organ culture have not contributed so much for the recent advances in physiology and pharmacology of the smooth muscle.

Transmural stimulation applied to the isolated guinea-pig taenia coli in the presence of atropine produced a relaxation of the taenia. In view of the evidence that this relaxation is resistant to adrenergic neuron blocking agents and to receptor blocking agents, it seems likely that this relaxation is due to the stimulation of non-adrenergic nerves (Burnstock et al. 1966, Rikimaru and Suzuki 1971). On the other hand, the relaxation produced by ganglion stimulants was susceptible to the blockade of adrenergic receptor blocking agents or to the treatment with reserpine (Weis 1962, Suzuki and Rikimaru 1971). Question arises whether the relaxation produced by ganglion stimulants involves a different mechanism from that produced by transmural stimulation. In this respect a denervation experiment is quite necessary to clarify the neural mechanism of these relaxing responses, but it cannot be achieved easily by cutting only the extrinsic nerves because of the presence of ganglion cells within the intestinal wall.

We adopted the method of organ culture to maintain the smooth muscle and to eliminate the effects of nervous elements. The nature of the inhibitory mechanisms of the intestinal smooth muscle of the guinea-pig taenia coli was studied more precisely. During these experiments comparison was made between the relaxation due to transmural stimulation and that due to nicotine with respect to the histochemical observations of the catecholamine fluorescence.

\section{Material and Methods}

\section{Method of organ culture}

Strips of taeniae were carefully dissected out from the caecal wall of the guinea-pig and cut in pieces, about $5 \mathrm{~mm}$ long. Tissues were then placed on the solid agar base in a Petri dish, and covered with a thin layer of soft agar warmed at $37^{\circ} \mathrm{C}$. The fluid nutrient was added, the amount used being just sufficient to cover the explants. Two groups of culture media were used in this experiment. In group A, the agar medium contained $1 \%$ of purified agar (Difeo) in a mixture of $60 \%$ Eagle's minimum essential medium (MEM), $30 \%$ horse serum and $10 \%$ chick embryo extract. The additional fluid nutrient consisted of $60 \%$ Eagle's MEM, 30\% horse serum and 10\% chick embryo extract. In group B, the agar medium contained $1 \%$ of purified agar in Earlge's MEM. The fluid nutrient, in this case, was composed of $80 \%$ Eagle's MEM and $20 \%$ horse serum. Eargle's MEM used in this study was supplemented with glucose to produce a final concentration of $500 \mathrm{mg} /$ $100 \mathrm{ml}$. Cultures were kept at $37^{\circ} \mathrm{C}$ in a humidified air-tight chamber which was gassed with $5 \% \mathrm{CO}_{2}$ and $95 \% \mathrm{O}_{2}$. The fluid nutrient was changed twice a week.

\section{Methods to observe the contractile properties of the cultured taenia}

The contractile properties of the taenia strips in each stage of culture were investigated isometrically with a strain-gauge transducer (Grass FT-10) and an ink writing oscillograph (Grass Model-5 Polygraph). For the selective stimulation of the intramural nervous elements, trains of square-wave pulses (1 msec duration) at different frequencies were delivered for 5 seconds transmurally to the taenia through bipolar stimulating electrodes made of $\mathrm{Ag}-\mathrm{AgCl}$ rings, about $2 \mathrm{~mm}$ apart. Longitudinal field stimulation with A.C. $(3 \mathrm{~V} / \mathrm{cm}, 50 \mathrm{~Hz}$ ) was given through $\mathrm{Ag}-\mathrm{AgCl}$ plate electrodes placed at both ends of the bath to stimulate the smooth muscle cells directly. 
The following drugs were used: acetylcholine chloride, noradrenaline hydrochloride, atropine sulphate, nicotine, 5 -hydroxytryptamine creatine sulphate, and tetrodotoxin. The doses are given in terms of the salt $(\mathrm{g} / \mathrm{ml})$.

Detection of catecholamine with fluorescence microscope

Tissue specimen were quickly frozen by isopentane precooled with dry ice-acetone, and cut in a cryostat at 10 or $20 \mu$ interval. The sections were stuck to a cover glass and dried for about 1.5 hours at room temperature over fresh $\mathrm{P}_{2} \mathrm{O}_{5}$. Then the dried sections were exposed to the moist formaldehyde vapor for $I$ hour at $80^{\circ} \mathrm{C}$ as described in detail by Falck and Owman (1965). After this procedure the sections were mounted in glycerol or in liquid paraffine with fluorescence-free slide glass and examined under the fluorescence micrscope (Tiyoda FM-200 A).

\section{RESULTS}

\section{Contractile responses of the taenia strips of group $A$}

As summarized in Table $1 \mathrm{~A}$, the taenia strips of group A were well maintained in their responsiveness to electrical stimulations and to drugs for more than three weeks. Fig. 1 shows an example of the taeniae cultured for three weeks. This preparation responded well to field stimulation with A.C. $(3 \mathrm{~V} / \mathrm{cm}, 50 \mathrm{~Hz})$ and to drugs directly acting on the smooth muscle such as acetylcholine $\left(10^{-6} \mathrm{~g} / \mathrm{ml}\right)$ and noradrenaline $\left(10^{-6} \mathrm{~g} / \mathrm{ml}\right)$. In the presence of atropine $\left(10^{-7} \mathrm{~g} / \mathrm{ml}\right)$, transmural stimulation ( $1 \mathrm{msec}, 5$ pulses $/ \mathrm{sec})$ and nicotine $\left(5 \times 10^{-6}-5 \times 10^{-5} \mathrm{~g} / \mathrm{ml}\right)$ could elicit relaxation of the taenia, which was easily abolished by tetrodotoxin $\left(10^{-8} \mathrm{~g} / \mathrm{ml}\right)$. These results suggest a long survival of the intramural neurons under these conditions. The medium of this group is, therefore, inadequate to exclude the nervous elements within the taenia. The following data in this paper were all obtained from the taenia preparations of group B.

TABLE 1. Responses of the organ-cultured taenia preparations to field stimulation with A.C. $(3 \mathrm{~V} / \mathrm{cm}, 50 \mathrm{~Hz})$, acetylcholine $\left(A C h, 10^{-6} \mathrm{~g} / \mathrm{ml}\right)$, noradrenaline $(N A$, $10^{-6} \mathrm{~g} / \mathrm{ml}$ ), nicotine (Nic, $5 \times 10^{-5} \mathrm{~g} / \mathrm{ml}$ ) and transmural stimulation $(T M, 1 \mathrm{msec}$, 5 pulses $/ \mathrm{sec})$. The results are expresed as follows: number of preparations responded/number of preparations tested.

\begin{tabular}{|c|c|c|c|c|c|c|}
\hline \multirow{2}{*}{ Group } & \multirow{2}{*}{$\begin{array}{l}\text { Stimulation } \\
\text { and drug }\end{array}$} & \multicolumn{5}{|c|}{ Stage of culture (days) } \\
\hline & & $1-5$ & $6-10$ & $11-15$ & $16-20$ & $21-25$ \\
\hline A & $\begin{array}{l}\mathrm{AC} \\
\mathrm{ACh} \\
\mathrm{NA} \\
\mathrm{NiC} \\
\mathrm{TM}\end{array}$ & $\begin{array}{l}7 / 7 \\
7 / 7 \\
7 / 7 \\
7 / 7 \\
7 / 7\end{array}$ & $\begin{array}{l}11 / 11 \\
11 / 11 \\
11 / 11 \\
11 / 11 \\
11 / 11\end{array}$ & $\begin{array}{r}10 / 10 \\
10 / 10 \\
10 / 10 \\
9 / 10 \\
9 / 10\end{array}$ & $\begin{array}{l}8 / 8 \\
8 / 8 \\
8 / 8 \\
8 / 8 \\
8 / 8\end{array}$ & $\begin{array}{l}5 / 5 \\
5 / 5 \\
5 / 5 \\
4 / 5 \\
4 / 5\end{array}$ \\
\hline B & $\begin{array}{l}\text { AC } \\
\text { ACh } \\
\text { NA } \\
\text { NiC } \\
\text { TM }\end{array}$ & $\begin{array}{l}5 / 5 \\
5 / 5 \\
5 / 5 \\
4 / 5 \\
4 / 5\end{array}$ & $\begin{array}{l}6 / 6 \\
6 / 6 \\
6 / 6 \\
5 / 6 \\
5 / 6\end{array}$ & $\begin{array}{l}9 / 9 \\
9 / 9 \\
9 / 9 \\
8 / 9 \\
8 / 9\end{array}$ & $\begin{array}{r}10 / 10 \\
10 / 10 \\
10 / 10 \\
3 / 10 \\
3 / 10\end{array}$ & $\begin{array}{r}12 / 12 \\
12 / 12 \\
12 / 12 \\
1 / 12 \\
1 / 12\end{array}$ \\
\hline
\end{tabular}




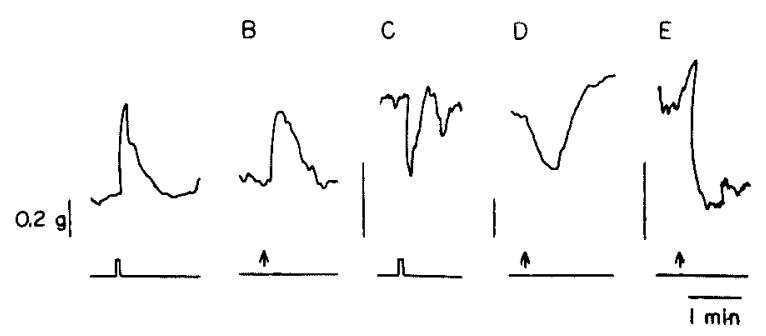

Fig. 1. Responses of the taenia preparation cultured for 21 days in the medium of group A. A, field stimulation with A.C. $(3 \mathrm{~V} / \mathrm{cm}, 50 \mathrm{~Hz})$; B, acetylcholine $10^{-6} \mathrm{~g} / \mathrm{ml}$; C, transmural stimulation (1 msec, 5 pulses $/ \mathrm{sec}$ ) in the presence of atropine $10^{-7} \mathrm{~g} / \mathrm{ml} ; \mathrm{D}$, nicotine $5 \times 10^{-5} \mathrm{~g} / \mathrm{ml}$ in the presence of atropine $10^{-7} \mathrm{~g} / \mathrm{ml} ; \mathrm{E}$, noradrenaline $10^{-8} \mathrm{~g} / \mathrm{ml}$.

\section{Spontaneous activities of the taenia}

Fig. 2 shows the typical spontaneous activities observed in cultured taenia strips. The taenia strips usually showed very irregular tonic and/or phasic contractions as shown in Figs. $2 \mathrm{C}$ and $2 \mathrm{D}$, but some preparations showed regular movements (Figs. $2 \mathrm{~A}$ and $2 \mathrm{~B}$ ). The latter types well responded to field stimulation with A.C. $(3 \mathrm{~V} / \mathrm{cm} .50 \mathrm{~Hz})$, whereas the former poorly responded to it. These spontaneous movements were not influenced by tetrodotoxin $\left(10^{-8}-5 \times 10^{-7} \mathrm{~g} / \mathrm{ml}\right)$, and could be observed in preparations which lost their responsiveness to transmural stimulation and to nicotine.

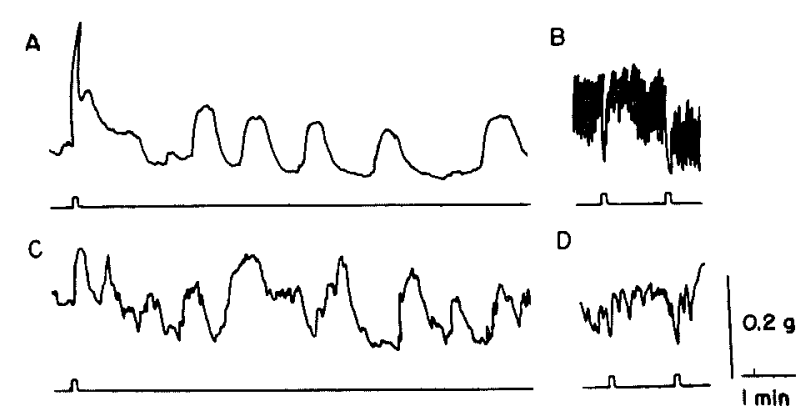

Fig. 2. Spontaneous activities of the cultured taeniae. A and C, tonic spontaneous contractions and the response to field stimulation with A.C. $(3 \mathrm{~V} / \mathrm{cm}, 50 \mathrm{~Hz})$ observed in taeniae on the 21 st day of culture. B and $\mathrm{D}$, phasic spontaneous contractions and the response to transmural stimulation ( $1 \mathrm{msec}, 5$ pulses/sec) in taeniae on the 14 th day of culture.

Contraction elicited by field stimulation with A.C.

Field stimulation of the taenia strips with A.C. $(3 \mathrm{~V} / \mathrm{cm}, 50 \mathrm{~Hz})$ produced contractions directly and indirectly, which were classified into three types by atropine $\left(10^{-7} \mathrm{~g} / \mathrm{ml}\right)$. As shown in Figs. $3 \mathrm{~A}$ and $3 \mathrm{~B}$, the first two types were susceptible to the blocking action of atropine and reduced or reversed to relaxations, whereas the third type (Fig. $3 \mathrm{C}$ ) showed no reduction at all. The susceptibility to atropine implies the presence of cholinergic excitatory nerves in 
these preparations. In fact, the preparations of the first two types showed contractions by transmural stimulation and by nicotine, though that of the third type did not. The first type, which was reversed to a relaxation after atropine, was observed in relatively early stage of culture (1-5 days of culture). The second type was the most usual type observed in the taenia strips cultured for one to two weeks, and the third type in more advanced stage of culture.

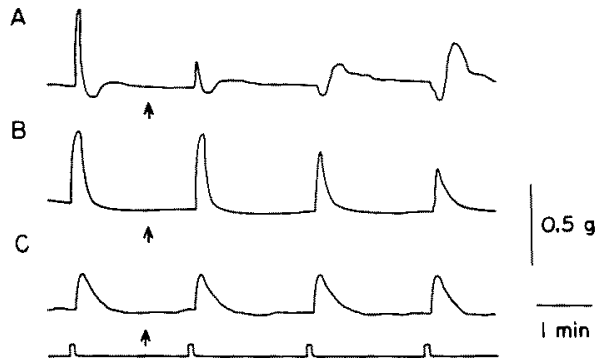

Fig. 3. Effect of atropine on the contraction produced by field stimulation with A.C. (3 V) $\mathrm{cm}, 50 \mathrm{~Hz}$ ). A, 4 days in culture; B, 10 days in culture; $\mathrm{C}, 21$ days in culture.

\section{Responses to transmural stimulation and to nicotine}

The taenia strips in the early stage of culture well responded to transmural stimulation ( $1 \mathrm{msec}, 5$ pulses $/ \mathrm{sec})$ and to nicotine $\left(5 \times 10^{-6}-5 \times 10^{-5} \mathrm{~g} / \mathrm{ml}\right)$, and resulted in relaxations or contractions. The relaxations were enhanced after atropine $\left(10^{-7} \mathrm{~g} / \mathrm{ml}\right)$, whereas the contractions were potentiated by physostigmine $\left(10^{-7}-10^{-6} \mathrm{~g} / \mathrm{ml}\right)$ and reversed to relaxations after atropine $\left(10^{-7} \mathrm{~g} / \mathrm{ml}\right)$. Fig. 4 shows an example of the taenia strips cultured for a week. This preparation showed marked relaxing responses to transmural stimulation ( $1 \mathrm{msec}, 5$ pulses/sec) and to nicotine $\left(5 \times 10^{-6} \mathrm{~g} / \mathrm{ml}\right)$ after atropine $\left(10^{-7} \mathrm{~g} / \mathrm{ml}\right)$. The most characteristic change observed at this stage is that transmural stimulation at high frequencies $(40-50$ pulses $/ \mathrm{sec})$ produced only a slight or no relaxation, whereas at low frequencies produced a large relaxation (Fig. 5). This tendency could be

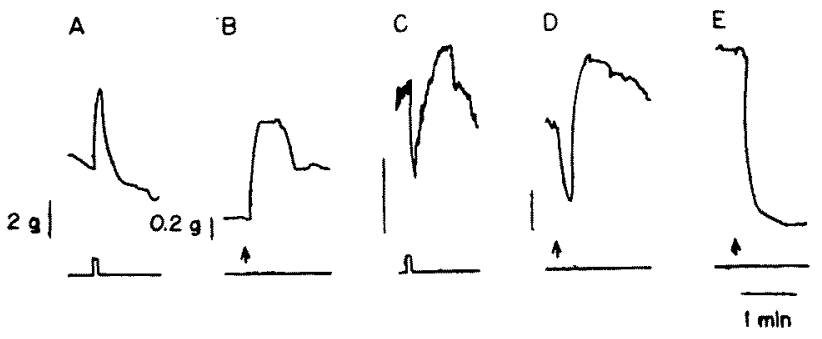

Fig. 4. Responses of the taenia on the 7th day of culture. A, field stimulation with A.C. (3 $\mathrm{V} / \mathrm{cm}, 50 \mathrm{~Hz}$ ); B, acetylcholine $10^{-6} \mathrm{~g} / \mathrm{ml} ; \mathrm{C}$, transmural stimulation (1 msec, 5 pulses $/ \mathrm{sec}$ ) in the presence of atropine $10^{-7} \mathrm{~g} / \mathrm{ml} ; \mathrm{D}$, nicotine $5 \times 10^{-5} \mathrm{~g} / \mathrm{ml}$ in the presence of atropine $10^{-7} \mathrm{~g} / \mathrm{ml} ; \mathrm{E}$, noradrenaline $10^{-6} \mathrm{~g} / \mathrm{ml}$. 


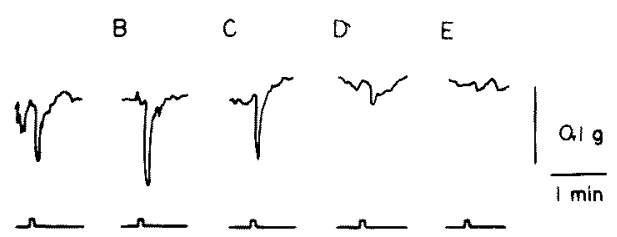

Fig. 5. The responses of the taenia to transmural stimulation ( $1 \mathrm{msec}$ ) at different frequencies in the presence of atropine $10^{-7} \mathrm{~g} / \mathrm{ml}$ observed on the 4 th day of culture. A, I; B, 5; C, 10; D, 30; E, 50 pulses/sec.

observed with taenia strips after three days of incubation. Soaking in $10^{-6}-10^{-5}$ $\mathrm{g} / \mathrm{ml}$ of noradrenaline for more than $30 \mathrm{~min}$ at $37^{\circ} \mathrm{C}$ did not recover the highfrequency responses. As demonstrated in our previous papar (Rikimaru and Suzuki 1971) and in that of Burnstock et al. (1966), the relaxation produced by transmural stimulation at high frequencies were greatly reduced or nearly abolished by adrenergic neuron blocking agents, and therefore such relaxation should be due to stimulation of sympathetic adrenergic nerves. These results imply that the degenerative change might occur in the sympathetic adrenergic nerves of the taeniae.

As summarized in Table 1B, most of the preparations lost their responsiveness to transmural stimulation and to nicotine after two to three weeks of incubation. But even at this stage (Fig. 6), they still responded to field stimulation with A.C. $(3 \mathrm{~V} / \mathrm{cm}, 50 \mathrm{H})$, acetylcholine $\left(10^{-6} \mathrm{~g} / \mathrm{ml}\right)$ and noradrenaline $\left(10^{-6} \mathrm{~g} / \mathrm{ml}\right)$, though the amplitudes of these responses gradually decreased. The responses to both trasmural stimulation ( $1 \mathrm{msec}, 5$ pulses $/ \mathrm{sec})$ and nicotine $\left(5 \times 10^{-6}-5 \times 10^{-5} \mathrm{~g} / \mathrm{ml}\right)$ disappeared at the same stage of culture. During this process, no dissociation could be observed between the excitatory and the inhibitory responses elicited by transmural stimulation and by nicotine. These results may suggest that in most preparations the intramural nervous elements were entirely degenerated after two to three weeks of incubation, and that the relaxations produced by transmural stimulation at low frequencies and by nicotine involve the same neural pathway within the taeniae.

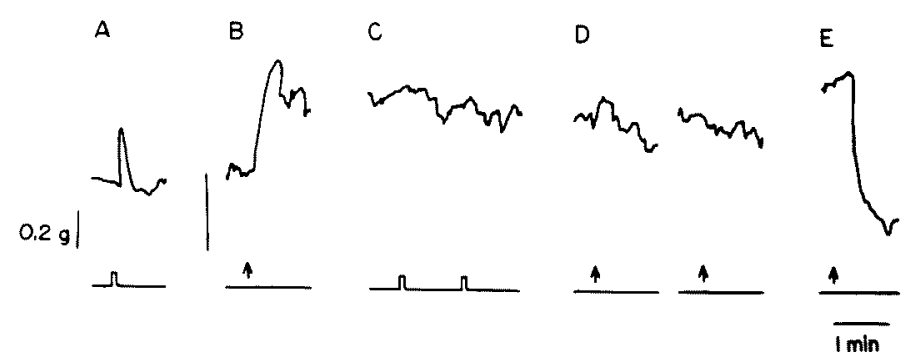

Fig. 6. Responses of the taenia on the 17th day of culture. A, field stimulation with A.C. $(3 \mathrm{~V} / \mathrm{cm}, 50 \mathrm{~Hz}) \mathrm{B}$, acetylcholine $10^{-6} \mathrm{~g} / \mathrm{ml} ; \mathrm{C}$, transmural stimulation (1 msec, 5 pulses $/ \mathrm{sec})$ in the presence of atropine $10^{-7} \mathrm{~g} / \mathrm{ml} ; \mathrm{D}$, nicotine $5 \times 10^{-6}$ and $5 \times 10^{-5} \mathrm{~g} / \mathrm{ml}$ in the presence of atropine $10^{-7} \mathrm{~g} / \mathrm{ml} ; \mathrm{E}$, noradrenaline $10^{-6} \mathrm{~g} / \mathrm{ml}$. 


\section{Responses to noradrenaline and to acetylcholine}

When an autonomic effector is denervated, it becomes increasingly sensitive to chemical agents. It is, therefore, predicted from this basis that after degeneration of the nervous elements, the organ-cultured intestinal smooth muscle may become supersensitive to acetylcholine and to noradrenaline. On the fourth day of culture, the relaxation produced by transmural stimulation at high frequencies were eliminated as shown previously (Fig. 5). This may imply the degeneration of the sympathetic adrenergic nerves. Noradrenaline was tried at this stage, but the threshold concentration of this drug to produce a relaxation of the taenia strips was usually 10 to 100 times higher than that of the taeniae before culture. Noradrenaline of $10^{-8}-10^{-7} \mathrm{~g} / \mathrm{ml}$ was needed to produce the minimal response. At this stage, the threshold concentration of acetylcholne was also increased to the same extent as that of noradrenaline. The sensitjvities to both agents gradually recovered to the preincubation levels after a week of incubation, but there was no sign of supersensitivity to noradrenaline even in more advanced stages. The results with acetylcholine showed the same tendency, and the threshold concentration was the same or rather higher than that of the taenias before culture. But in two preparations out of fourteen, reduction of the threshold concentration to acetylcholine was observed (Fig. 7). These preparations responded to acetylcoline of $10^{-10} \mathrm{~g} / \mathrm{ml}$, and the maximal response was produced at $10^{-7} \mathrm{~g} / \mathrm{ml}$.

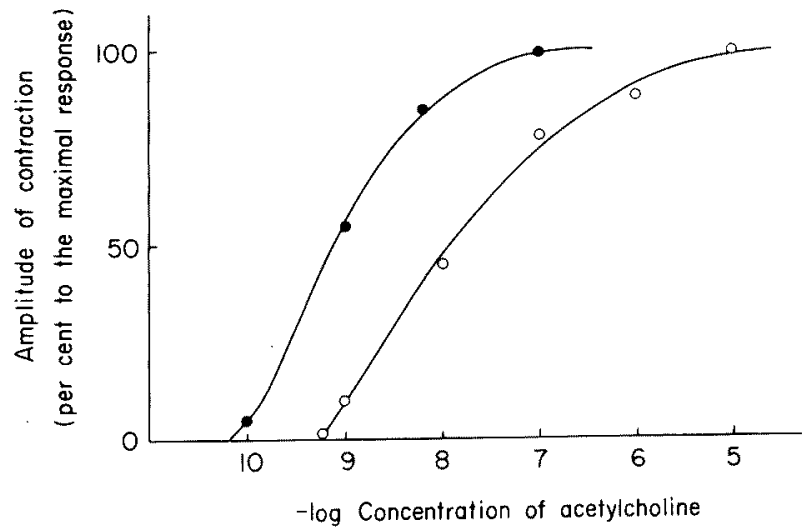

Fig. 7. Dose-response curves to acetylcholine. Open circles demonstrate the response before culture, and solid circles after 24 days in culture.

\section{Effects of 5-hydroxytryptamine}

It was suggested by Bucknell and Whitney (1964) that 5-hydroxytyptamine (5-HT) produced a relaxation in the human taenia coli due to its direct effect on the smooth muscle cells. Akubue (1966) confirmed this result in the guinea-pig taenia coli. But on the other hand, there is evidence indicating that the relaxation produced by 5-HT is indirectly elicited (Bülbring and Gershon 1967, Gershon 
1967, Rikimaru and Suzuki 1971). It was of great interest to examine whether 5-HT could directly elicit relaxation of the guinea-pig taenia coli. The experiments were carried out on five preparations cultured for more than three weeks. These preparations responded to acetylcholine $\left(10^{-6} \mathrm{~g} / \mathrm{ml}\right)$ and noradrenaline $\left(10^{-6} \mathrm{~g} / \mathrm{ml}\right)$, but none of them responded to transmural stimulation ( $1 \mathrm{msec}, 5$ pulses/sec) or to nicotine $\left(5 \times 10^{-6}-5 \times 10^{-5} \mathrm{~g} / \mathrm{ml}\right)$. Neither a contraction nor a relaxation was elicited by 5 -HT in concentrations up to $10^{-4} \mathrm{~g} / \mathrm{ml}$ as shown in Fig. 8 .

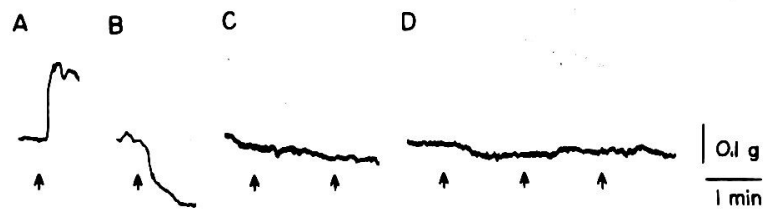

Fig. 8. Responses of the trenia to chemical agents on the 21 st day of culture. A, acetylcholine $10^{-6} \mathrm{~g} / \mathrm{ml} ; \mathrm{B}$, noradrenaline $10^{-6} \mathrm{~g} / \mathrm{ml} ; \mathrm{C}$, nicotine $5 \times 10^{-6}$ and $5 \times 10^{-5}$ $\mathrm{g} / \mathrm{ml} ; \mathrm{D}, 5$-HT $5 \times 10^{-6}, 10^{-5}$ and $5 \times 10^{-5} \mathrm{~g} / \mathrm{ml}$.

Localization of catecholamine fluorescence in the taenia coli before and after four days of incubation

Firstly, the localization of catecholamine fluorescence was examined in the taenia strips before culture. Very fine yellow-green fluorescent varicose fibers typical to adrenergic nerve terminals were seen to run parallel with the smooth muscle fibers of the taenia, in close proximity to them (Fig. 9). In Auerbach's plexus intensely fluorescent nerve fibers were arranged around the ganglion cells. None of the ganglion cells showed fluorescence characteristic for catecholamines even after treatment with monoamine oxidase inhibitor nialamide $(250 \mathrm{mg} / \mathrm{kg}$,

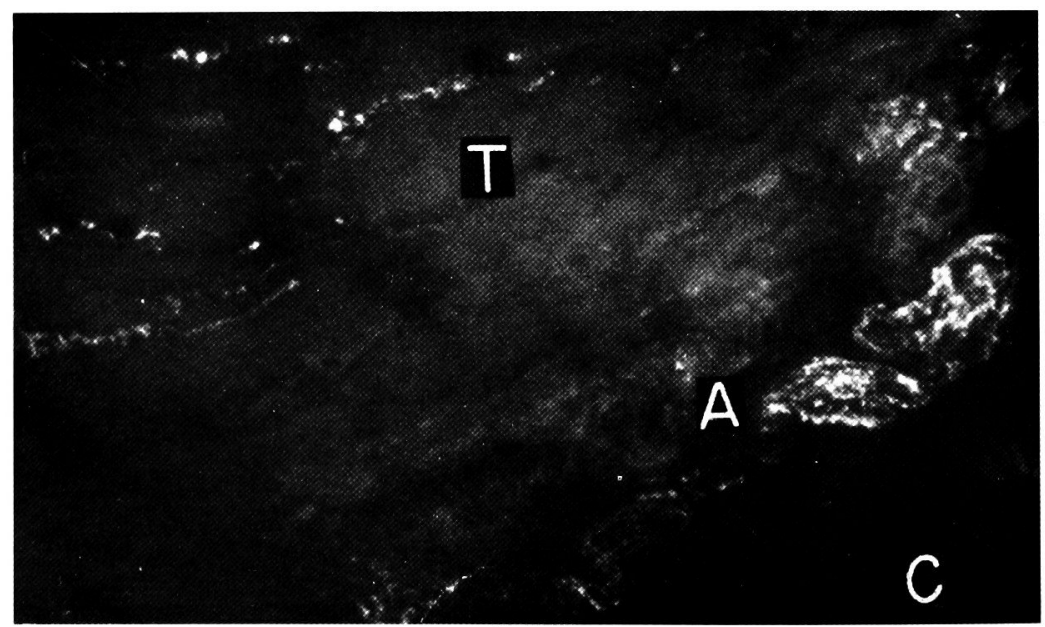

Fig. 9. Longitudinal section of the taenia before culture. Intensely fluorescent nerve fibers are scattered in the taenia $(\mathrm{T})$, and around the non-fluorescent ganglion cells in Auerbach's plexus (A). C, circular muscle layer. $\times 100$. 
intraperitoneal injection). In the guinea-pig taenia coli yellow fluorescence characteristic for 5-HT was never observed in Auerbach's plexus nor in the muscular layers.

Secondly, the localization of catecholamine fluorescence was examined in preparations cultured for four days. The fluorescent fibers which was observed in control preparations entirely disappeared and even a trace of them could not be seen at this stage (Fig. 10). This result may imply that the adrenergic nerves within the taeniae lost their activity at this stage of culture.

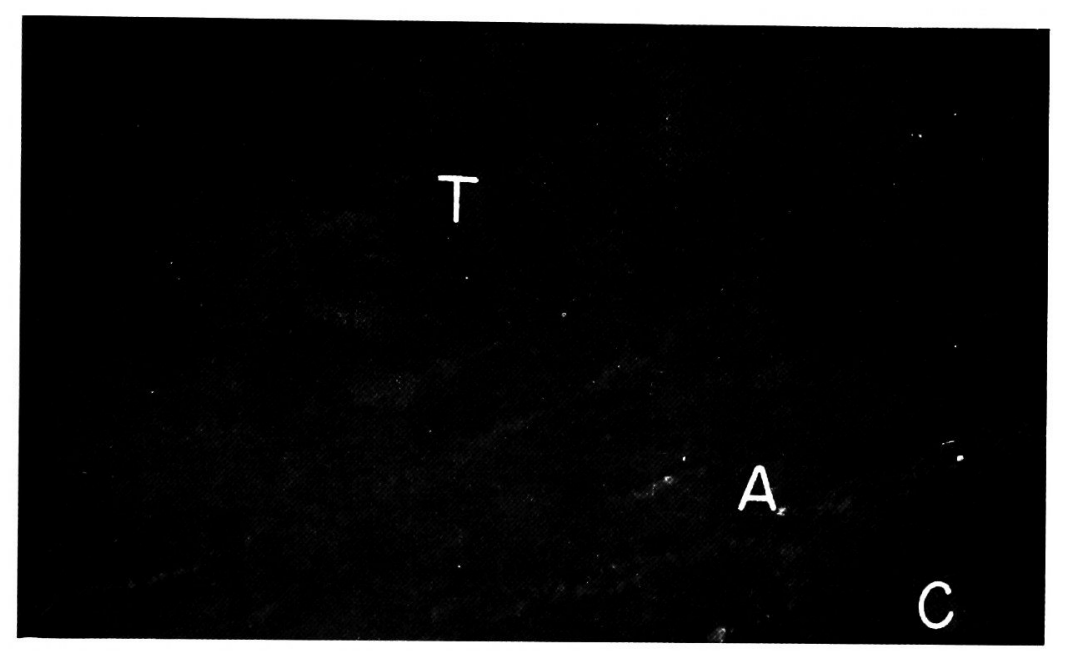

Fig. 10. Longitudinal section of the taenia on the 4th day of culture. No fluorescence characteristic for catecholamines could be observed in the taenia (T) and Auerbach's plexus (A). $\times 100$.

\section{Discussion}

Organotypic cultures of embyronic intestine were first carried out in 1922 by Chlopin (1922) and by Fischer (1922) independently. Since then publications have appeared dealing mainly with the differentiation of embyronic intestine, but there has as yet been scarce report which has concerned with the organ culture of adult intestine (see Borghese 1965). We attempted the organ culture of adult intestine to eliminate its nervous elements. Taeniae from guinea-pig caecum were cultured in media of different compositions. As a result, the taenia preparations of group A preserved their responsiveness to nicotine and to transmural stimulation for more than three weeks. This result may suggest the long survival of the intrinsic neurons under such condition. The agar medium and the fluid nutrient of this group contained 60\% Eagle's MEM, 30\% horse serum and 10\% chick embyro extract. Then the proportions of horse serum and of chick embyro extract were gradually reduced, and finally the taeniae were cultured in the agar medium containing only Eagle's MEM with the fluid nutrient containing 80\% Eagle's MEM 
and $20 \%$ horse serum. Most of the preparations lost their responsiveness to nicotine and to transmural stimulation after two to three weeks of incubation, though they still responded to directly acting agents. This result indicates that the nervous elements within the taeniae were eliminated in this condition after two to three weeks of incubation. Thus we chose the medium of group B for the following experiments.

Histofluorometric observations of the taeniae before culture failed to reveal any adrenergic nerve cells in Auerbach's plexus even after treated with monoamine oxidase inhibitor, though intensely fluorescent nerve fibers were observed abundantly in the musculature of the taeniae and around the non-fluorescent ganglion cells in Auerbach's plexus. These results were in good agreement with the previous reports (Hollands and Vanov 1965, Ảberg and Eränkö 1967, Bennett and Rogers 1967, Read and Burnstock 1969). After four days of incubation the taenia strips showed no fluorescence characteristic for catecholamines, and the response to transmural stimulation was essentially the same as that observed in the taeniae before culture treated with adrenergic neuron blocking agents (Burnstock et al. 1966, Rikimaru and Suzuki 1971). The response to high-frequency stimulation was greatly reduced or almost entirely abolished at this stage of culture. These results may suggest that the adrenergic nerves lost their activities either by degeneration or by exhaustion of their transmitter substance. As the relaxing response to transmural stimulation at high frequoncies was not recovered by soaking in the solution containing noradrenaline, this loss of response may be due to the degeneration of adrenergic nerves.

In our preceding report (Suzuki and Rikimaru 1971) we described that the relaxation produced by nictoine was abolished by adrenergic receptor blocking agents, whereas that produced by transmural stimulation was resistant to the blockade of these agents. It is possible, therefore, that the inhibitory effect of nitotine is due to release of catecholamine from adrenergic nerves. There is evidence to support this idea. Gillespie and MacKenna (1960) reported that the inhibitory effect of nicotine was abolished after pretreatment with reserpine and also after degenerative section of the extrinsic sympathetic nerves in rabbit colon. Weis (1962) made the same observation with reserpine in the guinea-pig taenia coli. Moreover, other workers have found that these inhibitory responses of intestinal preparation to nicotinic agents were abolished by bretylium (Greeff et al. 1962, Jarrett 1962, Burn and Gibbons 1964). Burnstock et al. (1966) observed in guinea-pig taenia coli that the relaxation produced by DMPP was abolished after high concentrations of adrenergic neuron blocking agents were applied. They postulated that this loss of response might be due to the ganglion blocking actions of these agents. If nicotine produced a relaxation due to a activation of the adrenergic nerves, this response might not be observed after degeneration of the adrenergic nerves. But this is not the case in cultured taeniae. The taenia preparations cultured for more than one week still responded to nictotine and to transmural stimulation at low frequencies, and resulted in relaxations in the 
presence of atropine. It is obvious from the histochemical data that the adrenergic nerves had already lost their activities at this stage, and the remaining response must, therefore, be due to activation of the non-adrenergic inhibitory nerves.

The possibilities of direct inhibition of the smooth muscle cell activities by nicotine and by transmural stimulation were excluded by the experiments using the taenia preparations in more advanced stage of culture. In most preparations the relazations produced by nicotine and by transmural stimulation disappeared after three weeks of incubation, though a relaxation could still be produced by addition of noradrenaline. Disappearance of these responses took place at the same stage of culture. These results suggest that both responses may involve the same neural pathway, and strongly confirm the presence of non-adrenergic inhibitory neurons in the guinea-pig taenia coli.

What is the transmitter substance of these intramural inhibitory neurons? Dopamine is recently believed to be the transmitter in the caudate nuclues (Portig et al. 1968) and in the carotid body (Dearnaley et al. 1968). Takagi et al. (1969) observed the effects of dopamine and its derivatives on guinea-pig taenia coli and proposed that the relaxing response elicited by nicotine might be due to release of dopamine. But this is not probable. Dopamine is known to show intense fluorescence similar to noradrenaline by condensation with formaldehyde vapor (Falck et al. 1962, Van Orden et al. 1966, Dearnaley et al. 1968). But as shown by the histofluorometric data, the taenia strips lost such characteristic fluorescence on the fourth day of culture, though they still responded to nicotine and to transmural stimulation and resulted in relaxations in the presence of atropine.

It is as yet not certain whother 5-HT plays an indispensable role in the regulation of the gastrointestinal movements. We proposed in our previous report (Rikimaru and Suzuki 1971) that both excitatory and inhibitory effects of 5-HT to guinea-pig taenia coli might be due to stimulation of the intramural excitatory and inhibotory nerves. This was confirmed by the results using taeniae cultured for more than three weeks. These preparations responded to acetylcholine and to noradrenaline but not to 5-HT nor to nicotine. Bülbring and Gershon (1967) proposed the participation of 5-hydroxytryptaminergic preganglionic fibers in the vagal inhibitory pathway to the guinea-pig stomach. But we failed to observe such 5-hydroxytryptaminergic nerve fibers in Auerbach's plexus of the guinea-pig taenia coli. At present we favor the opinion that the inhibitory nerves, which have their cell bodies in Auerbach's plexus, receive cholinergic preganglionic fibers though they are sensitive to 5-HT.

The rhythmic contractions of the intestine in organ culture attracted attention of the investigators engaged in the field of organ culture. The spontaneous contractions were at first thought to be neurogenic (Bisceglie 1932), but later Keuning (1948) cleared that the contractions are myogenic. In the cultured taeniae, tonic and/or phasic spontaneous contractions were observed. These contractions could be seen in preparations which lost their responsiveness to nicotine and to transmural stimulation, and may therefore be myogenic in nature. 
The preparations, showing regular movements, well responded to acetylcholine and to field stimulation with A.C., whereas those showing very irregular movements poorly responded to them. The smooth muscle cells might not be wll coordinated in the latter type. These results are consistent with that of tetrodotoxin. This toxin did not influence the spontaneous activities of the taeniae though it abolished all the nervous activities.

The fluorescence characteristic for catecholamines had entirely disappeared on the fourth day of culture. The same tendency was observed by Kasuya et al. (1969) in the denervation experiment of rat vas deferens. They observed the disappearance of fluorescence four days after excission of the hypogastric ganglia, and development of supersensitivity to noradrenaline, acetylcholine and some other chemical agents. But we failed to observe such supersensitivity to noradrenaline. Only a few preparations cultured for more than three weeks became supersensitive to acetylcholine. At this stag 3 the acotylcholinestarase activity was somewhat diminished especially in the muscular layer of the taeniae (unpublished data). The problem of supersensitivity in organ-cultured intestinal smooth muscle must require further study.

\section{Acknowledgments}

I wish to express my thanks to Prof. T. Suzuisi for his interest and guidance, and to Prof. Y. Shimizu and Mrs. Y. Aizu, Departmznt of Anatomy, Tohoku University School of Dental Medicine, for their technical advice ant assistance.

\section{References}

1) Aberg, G. \& Fränkö, O. Localization of noradrenaline and acetylcholinesterase in the taenia of the guinex-pig cascum. Acta physiol. scand., 1967, 69, 383-384.

2) Akubue, P.I. Inhibition of the taenia of the guinea-pig caecum by acetylcholine, nicotine or 5-hydroxytryptamine. J. Pharm. Pharmac., 1966, 18, 625-626.

3) Benett, M.R. \& Rogers, D.C. A study of the innervation of the taenia coli. J. Cell Biol., 1967, 33, 573-596.

4) Bisceglie, V. Studi sui tessuti espiantati. II. L'actività peristaltica degli espianti di intestina embrionale. Arch. exp. Zellforsch., 1932, 12, 86-101.

5) Borghese, E. Salivary gland, intestinal tract and pancreas. In: William, E.N. (editor), Cells and Tissues in Culture, Vol. II, Academic Press, New York, 1965, pp. $591-606$.

6) Bucknell, A. \& Whitney, B. A preliminary investigation of the pharmacology of the human isolated taenia coli preparation. Brit. J. Pharmacol., 1964, 23, 164-175.

7) Bülbring, E. \& Gershon, M.D. 5-hydroxytryptamine participation in the vagal inhibitory innervation of the stomach. J. Physiol., 1967, 192, 823-846.

8) Burn, J.H. \& Gibbons, W.R. The sympathetic postganglionic fibre and the block by bretylium; the block prevented by hexamethonium and imitated by mecamylamine. Brit. J. Pharmacol., 1964, 22, 549-557.

9) Burnstock, G., Campbell, G. \& Rand, M.J. The inhibitory innervation of the taenia of the guinea-pig caecum. J. Physiol., 1966, 182, 504-526.

10) Chlopin, N. Über in vitro Kulturen der embryonalen Gewebe der Säugetiere. Arch. mikr. Anat., 1922, 96, 435-493.

11) Dearnaley, D.P., Filenz, M. \& Woods, R.I. The identification of dopamine in the rabbit's carotid body. Proc. Roy. Soc. B, 1968, 170, 195-203. 
12) Falck, B., Hillarp, N. -A., Thieme, G. \& Torp, A. Fluorescence of catecholamines and related compounds condensed with formaldehyde. J. Histochem. Cytochem., $1962,10,348-354$.

13) Falck, B. \& Owman, C. A detailed methodological description of the fluorescence method for the cellular demonstration of biogenic monoamines. Acta Univ. Lund., 1965, Sect. II, No. 7, 1-23.

14) Fischer, A. Cultures of organized tissues. I. exp. Med., 1922, 36, 393-397.

15) Gershon, M.D. Effects of tetrodotoxin on innervated smooth muscle preparations. Brit. J. Pharmacol., 1967, 29, 259-279.

16) Gillerspie, J.S. \& MacKenna, B.R. The inhibitory action of nicotine on the rabbit colon. J. Physiol., 1960, 152, 191-205.

17) Greeff, K., Kasperat, H. \& Osswald, W. Paradoxe Wirkungen der elektrischen Vagusreinzung am isolierten Magen- und Herzvorhofpräparat des Meerschweinchens, sowie deren Beeinflussung durch Ganglienblocker, Sympathicolytica, Reserpin und Cocain. Naunyn-Schmiedeberg's Arch, exp. Path. Pharmak., 1962, 243, 528-545.

18) Harrison, R.G. Observations on the living developing nerve fibre. Proc. Soc. exp. Biol. Med., 1907, 4, 140-143.

19) Hollands, B.C.S. \& Vanov, S. Localization of catechol amines in visceral organs and ganglia of the rat, guinea-pig and rabbit. Brit. J. Pharmacol., 1965, 25, 307-316.

20) Jarrett, R.J. Action of nicotine on the rabbit muscular organ (ileo-colic sphincter). Brit. J. Pharmacol., 1962, 18, 397-404.

21) Kasuya, Y., Goto, K., Hashimoto, H., Watanabe, H., Munakata, H. \& Watanabe, M. Nonspecific denervation supersensitivity in the rat vas deferens 'in vitro.' Europ. J. Pharmacol., 1969, 8, 177-184.

22) Keuning, F.J. On the histogenesis of the autonomic nerve plexus of the intestines. An investigation with the aid of cultivation in vitro. Excerpta Med. Sec. 1, Anat. $2,1948,149-151$.

23) Murray, M.R. Muscle. In: Cells and Tissuue in Culture, Vol. II, edited by E.N. William, Acedemic Press, New York, 1965, pp. 311-372.

24) Portig, P.J., Sharman, D.F. \& Vogt, M. Release by tubocurarine of dopamine and homovanillic acid from the superfused caudate nucleus. J. Physiol., 1968, 194, $565-572$.

25) Read, J.B. \& Burnstock, G. Adrenergic innervation of the gut musculature in vertebrates. Histochemie, 1969, 17, 263-272.

26) Rikimaru, A. \& Suzuki, T. Neural mechanism of the relaxing responses of guinea-pig taenia coli. Tohoku J. exp. Med., 103, 303-315.

27) Suzuki, T. \& Rikimaru, A. Effect of phenoxybenzamine on the relaxing response of taenia coli. Tohoku J. exp. Med., 1971, 102, 415-416.

28) Takagi, K., Takayanagi, I. \& Ohta, K. Action of dopamine and its derivatives on the taenia caecum and tracheal muscle from the guinea-pig and the vas deferens from the rat. Jap. J. Pharmacol, 1969, 19, 604-612.

29) Van Orden, L.S., III, Bloom, F.E., Barrnett, R.J. \& Giarman, N.J. Histochemical and functional relationships of catecholamines in adrenergic nerve endings. I. Participation of granular vesicles. J. Pharmacol. exp. Ther., 1966, 154, 185-199.

30) Weis, J. Biphasic responses of guinea-pig's taenia coli induced by 1,1-dimethyl-4phenylpiperazinium iodide (DMPP). Acta Pharmacol. (Kbh.), 1962, 19, 121-128. 